\title{
Acute attack of gout precipitated by concomitant use of aspirin and diuretic in a rheumatic mitral stenosis patient
}

\author{
Dibbendhu Khanra, Shishir Soni, ${ }^{\ominus}$ Ramlal Ola, Bhanu Duggal
}

Cardiology, All India Institute of Medical Sciences, Rishikesh, Uttarakhand, India

\section{Correspondence to Dr Bhanu Duggal, bhanuduggalbmj@gmail.com}

Accepted 27 August 2019

Check for updates

(c) BMJ Publishing Group Limited 2019. No commercial re-use. See rights and permissions. Published by BMJ.

To cite: Khanra D, Soni S, Ola $R$, et al. BMJ Case Rep 2019;12:e232085. doi:10.1136/bcr-2019232085

\section{DESCRIPTION}

A 28 -year-old man from India, known to have rheumatic heart disease (RHD) with severe mitral stenosis (MS), presented with painful nodular swelling of multiple joints of hands and feet. $\mathrm{He}$ suffered rheumatic fever at 12 years of age and was on penicillin prophylaxis for 5 years and then stopped. He was diagnosed to have developed severe MS at the age of 20 years and is fairly asymptomatic on furosemide $20 \mathrm{mg} 12$ hours and metoprolol succinate $25 \mathrm{mg} 12$ hours. However, he had an exacerbation of shortness of breath with orthopnoea and pedal swelling 2 weeks ago. Cardiovascular examination revealed a thin built man with a blood pressure of $100 / 60 \mathrm{~mm} \mathrm{Hg}$ and an irregular pulse of 90 beats/min. The jugular venous pressure was not elevated, and hepato-jugular reflux was absent. The pulmonary component of the second heart sound was loud, and a parasternal heave was noted. An opening snap was heard after the second heart sound, and a long apical mid-diastolic murmur was detected along with presystolic accentuation. The 12-lead surface ECG revealed normal sinus rhythm. Two-dimensional echocardiography revealed thickened mitral leaflets suggestive of severe MS with mitral valve area of $1 \mathrm{~cm}^{2}$. The left atrium was enlarged $(46 \mathrm{~mm}$ in end-systole) with the presence of spontaneous echo contrast. Mild mitral regurgitation was noted. The dose of diuretic was increased to torsemide $20 \mathrm{mg} 12$ hours, which diminished his congestive symptoms.

One week later, the patient presented with painful small joints of hands, wrist, elbows, feet and heel with restricted movements. Boggy swelling over both the elbows was also noted. However, there was no early morning stiffness. There was no recent upper respiratory tract infection or diarrhoea. There was no history of recent travel or unprotected sexual intercourse. There was no urethral discharge, redness of eyes or rashes anywhere in the body. He does not smoke or drink alcohol. There was no family history suggestive of any haemoglobinopathy. He did not have any significant previous medical history or any previous history of gout. The serum uric acid on admission was $5 \mathrm{mg} / \mathrm{dL}$ (normal range, $2.3-6.0 \mathrm{mg} / \mathrm{dL}$ ). The serum creatinine concentration was $1.1 \mathrm{mg} / \mathrm{dL}$ (normal range, $0.6-0.9 \mathrm{mg} / \mathrm{dL}$ ).

His haemoglobin level was $14.5 \mathrm{~g} / \mathrm{L}$ (normal $14-16 \mathrm{~g} / \mathrm{L}$ in male) and total leucocyte count was $12 \times 10^{9} / \mathrm{L}$ (normal $4-11 \times 10^{9} / \mathrm{L}$ ). Erythrocyte sedimentation (ESR) rate in the first hour was $32 \mathrm{~mm}$ (normal range is $0-22 \mathrm{~mm} /$ hour for men). C reactive protein (CRP) was $5 \mathrm{mg} / \mathrm{dL}$ (normal CRP levels are below $3.0 \mathrm{mg} / \mathrm{L}$ ). Antistreptolysin O (ASO) titre was 120 Todd units (normal <166 Todd units). The worsening joint pain and congestive symptoms in a known patient of RHD without penicillin prophylaxis with high TLC, ESR and CRP were presumed to be due to acute rheumatic activity, and Aspirin was started in the dose of two $325 \mathrm{mg}$ tablets three times a day.

The patient returned back after another week with nodular swelling of fingers and toes, red and tender, with ulceration. On examination of the joints, tender nodular swellings were noted in multiple small joints of both the hands, wrists, feet and ankle, mostly confined to the extensor surfaces (figure 1A). A nodule on his right foot drained chalky, sanguineous material. He also had leg ulcers formed at sites of draining tophi. Radiogram of the joints revealed the presence of multiple well-defined 'punched-out' erosions in the proximal interphalangeal joint of right little finger (figure 1B), the interphalangeal joint and metatarsophalangeal joint of the right big toe (figure 1C) with sclerotic margins in a marginal and juxta-articular distribution, with overhanging edges. Hyperdense soft tissue swellings were noted over the fingers of both the hands.

Joint aspirate was also taken from the tophi of right and left fingers and left great toe using a 21-gauge needle. It yielded white, chalky material which demonstrated slender needle-shaped crystals along with multinucleated giant cells and chronic inflammatory infiltrate on light microscopy of the Giemsa-stained smears. Polarising microscopy of the stained smears revealed negatively birefringent crystals, consistent with monosodium urate (MSU) deposition confirming diagnosis of gout.

The clinical, radiographic and histopathological features of the joint involvement were suggestive of gout, and the patient was put on colchicines. Aspirin was stopped, and torsemide was reduced to $10 \mathrm{mg}$ 24 hours. The joint pain and swelling improved over a 72 hours and resolved over a period of 2 weeks without any further deterioration of shortness of breath. Penicillin prophylaxis was reinitiated. On follow-up, haemoglobin electrophoresis was done and was of normal pattern. HLA-B27 was also done, which was negative.

Young man with Asian enthnicity presenting with multiple swollen joints of hands and feet could be due to dactylitis secondary to haemoglobinopathies, gout, pesudogout, reactive arthritis and 

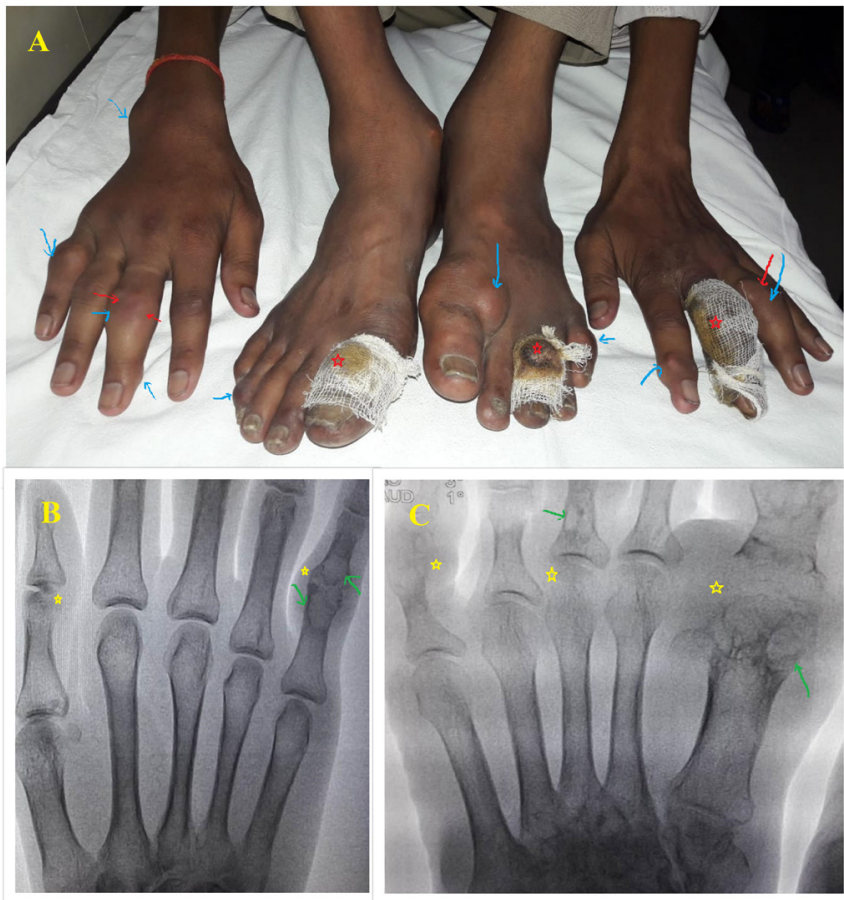

Figure 1 Image of multiple nodules (Tophi, blue arrows) overlying small joints of hands and feet (A) with overlying inflammation (red arrows) with discharging sinus (wrapped in gauzes, red stars). Radiogram of right hand (B) and feet (C) showing multiple well-defined 'punched-out' erosions (green arrows) with hyperdense soft tissue swellings (yellow stars).

rarely rheumatic arthritis. Normal haemoglobin electrophoresis ruled out heamoglobinopathy in our case. The absence of rash and preceding infection ruled out reactive arthritis. Rheumatic arthritis usually involves large joints, and dramatic response to aspirin is classical. Often subcutaneous nodules, worsening of cardiac symptoms and appearance of new (or musical) murmur, worsening regurgitation and pericardial effusion in echocardiography are associated. Moreover, rheumatic arthritis rarely causes erosion or deformity of joints. Recurrence of rheumatic arthritis was unlikely in our case to involve small joints of hands without elevation of ASO titre and, retrospectively, without response to aspirin. Moreover, the absence of calcification was noteworthy in the radiogram, which is common in pseudogout but absent in gout. However, joint aspirate demonstrating needle-shaped crystal with negative birefringence on polarised light is diagnostic of MSU deposition due to gout.

This case taught us many lessons. First, the presumptive diagnosis of acute rheumatic activity on the basis of worsening symptoms and elevated TLC, ESR and CRP was wrong. As in acute gouty arthritis, the inflammatory markers are also elevated. Second, a normal serum urate level misled us to rule out gout. But, serum uric acid level can be normal in acute attack of gout. In a study by Schlesinger et al, in 70\% of patients, the serum uric acid was lower during the acute episode. ${ }^{1}$ Moreover, the low uric acid level has been found to be correlated with increased inflammatory factors, which is also true in our case. ${ }^{2}$ Third, high-dose diuretic inducing gout is a known entity but rarely encountered and should be remembered by the cardiologists, while prescribing diuretics in RHD, heart failure or hypertension patients. It is usually associated with hyper-uricaemia but normal serum urate level does not exclude gout. ${ }^{3}$ Fourth, recurrent rheumatic activity is not uncommon in established RHD (even without the elevation of ASO titre in indolent cases), and 90\% patients suffer recurrence in their lifetime. However, it should be remembered that small joint involvement is a red-flag sign for rheumatic arthritis. ${ }^{4}$ Fifth, aspirin is the most effective treatment for acute rheumatic activity but it is also known to precipitate gout. Aspirin doses up to $1-2 \mathrm{~g} /$ day reduce uric acid excretion. ${ }^{5}$ In our patient, total dose of aspirin was $1950 \mathrm{mg}$ daily, which precipitated acute attack of gout probably with an additive effect of loop diuretic. Sixth, the radiological features of gout consist of well-defined 'punched-out' erosions with sclerotic margins without peri-articular osteopenia unlike non-erosive changes of rheumatic arthritis. ${ }^{6}$ Seventh, rheumatic arthritis is diagnosed retrospectively by the dramatic response of aspirin, likewise, gout is retrospectively diagnosed by its dramatic response with colchicine. Arthritis in our patient did not respond to aspirin but colchicines remarkably relieved the pain within 72 hours. Finally, our patient presented with tophi as an initial presentation of gout, which is very rare, but has been reported in the context of acute illness. ${ }^{7}$ In our case, concomitant recurrent rheumatic activity might play role, though there was no musical murmur, pericardial effusion, nodularity of mitral leaflets or elevation of ASO titre. ${ }^{8}$ In this regard, it is worthwhile to mention that there are cases which reported tophi in mitral valve in severe tophaceous gout. ${ }^{9}{ }^{10}$ However, tophaceous deposits in the mital valve were not seen in our case.

From a pharmacological point of view, loop diuretics inhibits, involved in the active uptake of plasma uric acid in renal proximal tubules. Loop diuretics increases serum uric acid levels by inhibiting Organic Anion Transporters (OAT1 and OAT3) located in basolateral portion of renal proximal tubules, inhibiting NPT4 which is located at the apical side of renal proximal tubules and also by inhibiting Multidrug Resistance Protein 4 (MRP4)-mediated uric acid transport. ${ }^{11}$ Moreover, diuretics cause sufficient salt and water loss that may to lead to volume contraction, which stimulates uric acid reabsorption. ${ }^{11}$ Also, furosemide induces hyperlactacidaemia sufficient to suppress tubular excretion of uric acid. ${ }^{11}$ In low dosages (60-300 mg once daily), aspirin reduces uric acid excretion and may induce hyperuricaemia, whereas higher doses are uricosuric. ${ }^{12}$ This paradoxical effect of salicylate can be explained by two modes of salicylate interaction with the urate monocarboxylate exchanger (URAT1): acting as an exchange substrate to facilitate urate reabsorption at low dose and acting as an inhibitor for urate reabsorption at high dose. In addition, salicylate may exert its hyperuricaemic effect through inhibiting MRP4-mediated urate transport as well as inhibiting OAT1 and OAT3. ${ }^{12}$

In our case, rheumatic MS patient presenting with worsening congestive symptoms with painful small joints was misdiagnosed as recurrence of rheumatic activity and was treated with aspirin

\section{Learning points}

- Serum uric acid level can be normal in acute attack of gout in up to $70 \%$ of cases and low uric acid level has been found to be correlated with increased inflammatory factors.

- Although $90 \%$ patients with rheumatic heart disease suffer recurrence of rheumatic activity in their lifetime, small joint involvement is a red-flag sign for rheumatic arthritis.

- Aspirin can precipitate acute attack of gout specially when used concomitantly with high-dose diuretics.

- Gout usually flares up during an acute illness, and rarely it can also present with tophi as an initial manifestation. 
and high dose of loop diuretics that precipitated gouty arthritis, which was later diagnosed correctly by its radiological appearance and was treated successfully with colchicines and diminution of dose of diuretics. In this regard, it is prudent to mention that, if diagnostic dilemma between gout and rheumatic arthritis cannot be resolved with confidence, it is worthy to give a trial of steroids, though, we did not try that in our case.

Contributors Conception: RO, DK. Case report: SS, RO. Investigations: RO, SS. Discussion: BD, DK. Critical appraisal: BD, DK.

Funding The authors have not declared a specific grant for this research from any funding agency in the public, commercial or not-for-profit sectors.

Competing interests None declared.

Patient consent for publication Obtained.

Provenance and peer review Not commissioned; externally peer reviewed.

\section{REFERENCES}

1 Schlesinger N, Baker DG, Schumacher HR, et al. Serum urate during bouts of acute gouty arthritis. J Rheumatol 1997:24:2265-6.

2 Bădulescu M, Macovei L, Rezuş E. Acute gout attack with normal serum uric acid levels. Rev Med Chir Soc Med Nat lasi 2014:118:942-5.
3 McAdams DeMarco MA, Maynard JW, Baer AN, et al. Diuretic use, increased serum urate levels, and risk of incident gout in a population-based study of adults with hypertension: the Atherosclerosis Risk in Communities cohort study. Arthritis Rheum 2012:64:121-9.

4 Sanyal SK, Thapar MK, Ahmed SH, et al. The initial attack of acute rheumatic fever during childhood in North India; a prospective study of the clinical profile. Circulation 1974;49:7-12

5 YU TF, Gutman AB. Study of the paradoxical effects of salicylate in low, intermediate and high dosage on the renal mechanisms for excretion of urate in man. J Clin Invest 1959;38:1298-313.

6 Chowalloor PV, Siew TK, Keen HI, et al. Imaging in gout: a review of the recent developments. Ther Adv Musculoskelet Dis 2014;6:131-43.

7 Sanyal SK, Berry AM, Duggal S, et al. Sequelae of the initial attack of acute rheumatic fever in children from north India. A prospective 5-year follow-up study. Circulation 1982;65:375-9.

8 Wernick R, Winkler C, Campbell S. Tophi as the initial manifestation of gout. Report of six cases and review of the literature. Arch Intern Med 1992:152:873.

9 Rohani A, Chamanian S, Hosseinzade P, et al. A case of mitral valve tophus in a patient with severe gout tophaceous arthritis. J Clin Imaging Sci 2012;2:68.

10 lacobellis $\mathrm{G}$, lacobellis $\mathrm{G}$. A rare and asymptomatic case of mitral valve tophus associated with severe gouty tophaceous arthritis. J Endocrinol Invest 2004·27:965-6.

11 Ben Salem C, Slim R, Fathallah N, et al. Drug-induced hyperuricaemia and gout. Rheumatology 2017;56:679-88.

12 Ohtsu N, Anzai N, Fukutomi T, et al. [Human renal urate transpoter URAT1 mediates the transport of salicylate]. Nihon Jinzo Gakkai Shi 2010;52:499-504.

Copyright 2019 BMJ Publishing Group. All rights reserved. For permission to reuse any of this content visit https://www.bmj.com/company/products-services/rights-and-licensing/permissions/ BMJ Case Report Fellows may re-use this article for personal use and teaching without any further permission.

Become a Fellow of BMJ Case Reports today and you can:

- Submit as many cases as you like

- Enjoy fast sympathetic peer review and rapid publication of accepted articles

- Access all the published articles

Re-use any of the published material for personal use and teaching without further permission

\section{Customer Service}

If you have any further queries about your subscription, please contact our customer services team on +44 (0) 2071111105 or via email at support@bmj.com.

Visit casereports.bmj.com for more articles like this and to become a Fellow 